2017-05-22

\title{
Autism and attachment difficulties: overlap of symptoms, implications and innovative solutions
}

mckenzie or stancer, rebecca

http://hdl.handle.net/10026.1/9307

\section{$10.1177 / 1359104517707323$}

Clinical Child Psychology and Psychiatry

SAGE Publications

All content in PEARL is protected by copyright law. Author manuscripts are made available in accordance with publisher policies. Please cite only the published version using the details provided on the item record or document. In the absence of an open licence (e.g. Creative Commons), permissions for further reuse of content should be sought from the publisher or author. 


\section{Autism and attachment difficulties: Overlap of symptoms, implications and innovative solutions}

Clinical Child Psychology and Psychiatry

$1-17$

(C) The Author(s) 2017

Reprints and permissions:

sagepub.co.uk/journalsPermissions.nav DOI: $10.1177 / 1359104517707323$

journals.sagepub.com/home/ccp

@SAGE

\author{
Rebecca McKenzie and Rudi Dallos \\ Plymouth University, UK
}

\begin{abstract}
This article explores overlap of symptoms between autism and attachment difficulties and suggests innovative solutions based on formulation. Currently, clinicians express difficulties in differentiating between these conditions contributing to misdiagnosis. Research into the prevalence of attachment difficulties among children with autism often fails to reflect detailed knowledge of attachment theory. Consequently, studies in this area employ questionable modifications to attachment measures and methods of analysis. The findings of such studies are confusing and inconsistent. Children with autism and their parents are, however, known to be at high risk of developing insecure attachment patterns. Clinical assessments based on formulation may be helpful in these cases, as they include consideration of developmental and relational factors contributing to symptom presentation. Research suggests that where parents of children with autism establish secure relationships with their children outcomes are improved. Consequently, interventions, which improve dyadic synchrony and sensitivity of parents, are likely to benefit families living with autism and attachment difficulties.
\end{abstract}

\title{
Keywords
}

Autism, formulation, attachment, diagnosis, development

\section{Background}

Clinicians identify substantial overlap of symptoms between attachment difficulties and autism spectrum disorder, but there is minimal discussion in the research literature around this topic. Consequences include difficulties in distinguishing between the two conditions, making the diagnostic process more complex and increasing the risk of misdiagnosis. Autism spectrum disorder (henceforth referred to as autism) is largely held to be a developmental disorder with a genetic component. Diagnostic criteria (American Psychiatric Association [APA], 2013) define autism as being characterized by two core features: deficits in social communication and social interaction, and restricted patterns of behaviour. The severity and presentation of these symptoms show an extreme degree of variation; hence, autism is defined as a 'spectrum condition'. 
The symptoms of autism are present in early childhood and continue throughout the lifespan. In the first two years of life, social deficits most clearly distinguish children who go on to receive a diagnosis of autism from those with other conditions or typical development. Specifically, a lack of joint attention, failure to show interest towards others, lack of shared play and not responding when called (Ozonoff, Williams, \& Landa, 2005). In addition to the core features of autism, children with this diagnosis commonly present with a range of additional symptoms, including sleep disorders, gastro-intestinal problems and psychological disorders, in particular anxiety and depression (Mazzone \& Vitiello, 2016).

The lack of a definitive cause for autism makes diagnosis a difficult process. There are no clearly identified biological markers for autism and assessment relies on input from a multi-disciplinary team and observational measures such as the Autism Diagnostic Schedule (ADOS). Difficulties also arise from the fact that autism has wide variation in presentation. Additionally, autism shares both core and secondary symptoms with other conditions including attachment difficulties.

Insecure attachment patterns, including reactive attachment disorder (RAD; henceforth collectively referred to as attachment difficulties) stem from early interactions between infant and primary figures in their life. Mary Ainsworth's (Ainsworth, Blehar, Waters, \& Wall, 1978) observational studies via the Strange Situation Protocol (SSP) revealed predictable attachment patterns, specifically Avoidant (A), Secure (B) and Anxious-Ambivalent (C). Main and Solomon (1986) added the disorganized category (D), known to reflect severe mistreatment. Insecurity of attachment may stem from neglect and abuse, separations, institutionalization, or everyday family interactions. Caregiving need not be abusive or purposefully negligent to result in insecure attachment and can result from the inadvertent intrusions of the parents' own difficult experiences. RAD, however, is character is thought to develop as a consequence of maltreatment or neglect in childhood, loss of parents or fearful interactions with traumatized parents. The characteristics include difficulties with empathy; unusual eating habits; conduct and emotional problems, including anxiety and depression; and problems with peer relationships (Stinehart, Scott, \& Barfield, 2012). It is sometimes assumed that these difficulties lead to permanent damage to children's attachment security but, some approaches, such as the Dynamic Maturational Model of attachment and adaptation (DMM; Crittenden, 2006) offers more emphasis on high-risk populations and also on potential for changes in attachment strategies across generations.

A young child may experience insecurity regardless of whether the parents' intentions were deliberately destructive or not. As children mature, however, realization of parents' negative intentions may add to a sense of insecurity and potential for emergence of more severe symptoms, such as higher levels of anxiety, communicational difficulties and anger.

Although the causes of attachment difficulties and autism are said to vary, the resulting symptoms are similar leading to a lack of clarity surrounding the comorbidity of the two conditions. Diagnostic and Statistical Manual of Mental Disorders (5th ed.; DSM-5; American Psychiatric Association [APA], 2013) criteria states that diagnosis for RAD should only be given where the child does not meet criteria for autism spectrum disorder, but this opens up possibilities for misdiagnosis if there is not a careful consideration of prior history. A critical review of the available literature leads us to predict that children diagnosed with autism are likely to fall into one of three groups. Those with autism and secure attachment, those with autism and insecure attachment and those who have been misdiagnosed and have core attachment related difficulties. Research exploring the prevalence of attachment problems among children with autism, however, includes conflicting findings. Many studies are based on oversimplifications of attachment theory, for example, reducing the subtle differences between attachment patterns to binary secure versus insecure 
classifications. In addition, relational and developmental issues, which may help researchers and clinicians to understand symptoms are often treated overcautiously or ignored.

Although the literature is confusing, children with autism and their families may be at increased risk of developing insecure attachment patterns because of a lack of communicative and social competence associated with autistic symptoms and the prevalence of similar traits and mental health problems among family members. As well as the pressing issue of misdiagnosis, children who exhibit symptoms of both autism and attachment difficulties present particular challenges for clinicians seeking to understand their symptoms and provide appropriate support. This article seeks to critically review available studies on attachment and autism, consider the nature of the overlap of symptoms, discuss implications and suggest innovative solutions.

\section{Overlap of symptoms and misdiagnosis}

Overlap of symptoms between attachment difficulties and autism appears in children with all forms of insecure attachment (Davidson et al., 2015; Moran, 2010; Rutter et al., 1999; Sadiq et al., 2012). Moran (2010) identifies the following eight symptoms which occur in both autism and attachment difficulties: inflexibility, atypical play, poor social interaction, problems with Theory of Mind, poor communication, deficits in emotional regulation, problems with executive function and sensory integration difficulties. The similarity of primary and secondary symptoms of autism and attachment difficulties has not been extensively explored, but there are some sources highlighting difficulties in distinguishing between autism and attachment difficulties and the consequent risk of misdiagnosis or unrecognized additional difficulties associated with insecure attachment.

For example, Sadiq et al. (2012) compared children with RAD, children with autism and typically developing children on measures to assess autistic symptoms, including the Autism Diagnostic Interview-Revised, Children's Communications Checklist and assessments by parents and clinicians. Many of the children with RAD showed symptoms commensurate with an autism diagnosis, including $46 \%$ having scores within the clinical range for 'reciprocal and social interaction' and $62.9 \%$ having scores within the clinical range for 'use of language and social communication skills'. Of the children assessed by clinicians, $60 \%$ were found to have symptoms that looked like autism.

Similarly, clinical evaluations of children adopted from institutions or foster homes characterised by insufficient care identify high levels of autistic traits, even though the case history indicates attachment difficulties as being the core problem (Rutter et al., 1999). Prevalence of autism in the United Kingdom is currently estimated to be $1 \%$ of the population. In the case of the Romanian adoptees studied by Rutter and colleagues, $6 \%$ met criteria for autism and another $6 \%$ had high autistic traits. A comparable study in Holland by Hoksbergen, Laak, Rijk, Dijkum and Stoutjesdijk (2005) reported similar results among 80 children who were adopted out of Romanian orphanages into Dutch families. Green, Leadbitter, Kay and Sharma (2016) also found 11\% of children entering adoption after early family breakdown, neglect or maltreatment showed high incidence of all autistic symptoms with a further $18.5 \%$ showing some symptoms.

These children's past experiences strongly indicate attachment problems; many are given a diagnosis of autism, yet when settled in nurturing families their symptoms of autism subside, suggesting incorrect diagnoses. Children 'looked after' by the local authority in the United Kingdom who would be expected to have attachment problems are also over-represented among children with autism, suggesting misdiagnosis or at least the lack of recognition of additional attachment problems. For example, Meltzer, Gatward, Corbin, Goodman and Ford (2003) studied adolescent boys in the care of the local authority and found that $8 \%$ of them met diagnostic criteria for autism. 
In cases where there is well-documented neglect or abuse, we might expect the diagnosis to be attachment related, but $D S M-V$ criteria only points to diagnosis for RAD where the child does not meet criteria for autism spectrum disorder. It is likely that many children suspected of attachment difficulties will meet criteria for autism, however, and this may preclude investigation of prior care, consequently autism will take precedence over RAD in the diagnostic process. Even if investigation of prior care does take place experts in attachment theory question the necessity of extreme forms of insufficient care in the backgrounds of children with insecure attachment. Cassidy and Shaver (2008), for example, emphasize that attachment problems can occur as a consequence of processes of 'ordinary' family life. What is important is the quality of the attachment relationships, and this features the ability of parents to be sensitively attuned to the child's needs. Many parents may be attempting to do the 'right' things with their child and are not neglectful, but are impeded (through post-natal depression, for example) or have not learnt from their own attachment experiences how to act in sensitive and attuned ways with their infants. Where no case history is available or where attachment difficulties stem from more subtle disruptions in the caregiver-child relationships the diagnostic process may be even more challenging. Current clinical strategies to deal with this state of affairs are limited and focus predominantly on attempts to develop detailed assessment criteria, such as the Coventry Grid (Moran, 2010).

Moran (2010) describes clearly the difficulties clinicians have in distinguishing between these two conditions and the rationale for developing The Coventry Grid, a detailed set of descriptors aiming to document differences in the presentation of common symptoms. The Coventry Grid is valuable in acknowledging the problems clinicians face, but highlights common misconceptions about attachment theory, which simplify attachment patterns into secure and insecure categories without regard for important differences in insecure attachment strategies. The format of the grid includes a number of areas where symptoms overlap such as 'emotional regulation' and 'poor social interaction'. It then seeks to provide statements showing differences in symptom presentation between autism and attachment difficulties for each area. The statements for attachment difficulties fail to include many behaviours found among anxious avoidant children, which are very similar to those found in autism. For example, under the 'Emotional regulation' section of the grid, presentation among those with attachment difficulties is described by the following statement:

May provoke extreme emotional reactions in others which tend to cast others in roles which are familiar from their own past experience of less healthy relationships. (Moran, 2010, p. 56)

This statement, however, describes behaviour typical of children with the disorganized attachment pattern and does not differentiate this from the other forms of insecure attachment, such as the anxious avoidant pattern which more closely parallels the emotional withdrawal and pre-occupation with objects (rather than people) found in autism.

In effect, the Coventry Grid conflates different insecure attachment styles. Analysis of the Grid employing a more detailed and differentiated use of attachment theory demonstrates, therefore, that the overlap of symptoms is more pervasive than Moran suggests and that in some cases the two conditions are not distinguishable. This possibility raises questions about current diagnostic procedures and suggests the need for a more individualized approach to assessment and intervention.

\section{Measures of attachment security among children with autism}

Although some children who have attachment difficulties may be misdiagnosed as having autism, others may have both autism and attachment difficulties. Modifications made to measures used in studies exploring attachment insecurity among children with autism are, however, problematic. 
Most studies use versions of the SSP or the Attachment Q-Sort (AQS Waters \& Deane, 1985), the most widely used measure being the SSP. It is arguable that modifications to the measure and its use outside of the age group for which it was intended reveal misconceptions about attachment theory and possibly invalidate research findings.

The SSP relies on the fact that attachment patterns are apparent at times of danger such as separation from the caregiver. Children are highly dependent on caregivers to ensure their safety and separations from the caregiver elicit distress especially in younger children who may not comprehend when or if the parent will return. This heightened sense of danger causes attachment strategies to come into play (Ainsworth et al., 1978). Most studies in this area use adapted versions of the SSP, where a brief separation is initiated within a play situation (Willemsen-Swinkels, Bakermans-Kranenburg, Buitelaar, van IJzendoorn, \& Van Engeland, 2000), in some cases this involves a statement by the parent that they will be 'right back' if the child protests at the separation (Grzadzinski, Luyster, Spencer, \& Lord, 2014, p. 89). Reasons for the shortening of the separation and inclusion of just one separation are rarely given, although this effectively invalidates the measure. Where reasons for adapting the SSP are given they refer to the difficulties children with autism have in coping with unexpected changes in routine or the fact that children with autism find separations 'quite distressing' (Rutgers, Bakermans-Kranenburg, van IJzendoorn, \& van Berckelaer-Onnes, 2004, p. 1124). Yet without some level of distress attachment behaviours will not be activated.

Further difficulties arise in analysis of the modified SSP since experimenters have sought to identify and disregard behaviours, which are caused by autism. For example, some studies have identified very high levels of disorganized attachment among children with autism, but have then removed recorded instances of behaviour attributed to autism before re-analysing the data, resulting in significant re-classification of attachment patterns (Capps, Sigman, \& Mundy, 1994; Willemsen-Swinkels et al., 2000). In the case of the Capps et al. study, for example, all of the children with autism were initially found to display disorganized attachment patterns, but re-classification resulted in secure attachment patterns being increased from $0 \%$ of children to $40 \%$. Such re-classification should be viewed with caution. As we have seen, autism and attachment difficulties result in similar symptoms and even very experienced clinicians find identifying which symptoms are attributable to autism extremely challenging.

A further problem with the use of the SSP to assess attachment security among children with autism is the age at which they are tested. Despite the fact that the SSP was specifically designed for children between the ages of 9 and 18 months, many studies include children who are well over 18 months and do not have intellectual disability. For example, among the 16 studies included in the Rutgers et al. (2004) meta-study, only 3, using the SSP or modified SSP, included children in this age group (Bakermans-Kranenburg, Rutgers, Willemsen-Swinkels, \& van IJzendoorn, 2003; Shirataki, 1994; Spencer, 1993). In these 3 studies, children with autism displayed high levels of attachment insecurity compared to other groups.

Other studies in the Rutgers et al. (2004) meta-analysis found less attachment insecurity among children with autism based on the SSP, but these studies included children with autism aged up to 69 months with and without intellectual impairment. Older children are more likely to be left alone for short periods and have more extensive experience of a parent returning. They are also able to enquire about the separation. Attachment relationships also change over time with older children being less reliant on constant caregiving. Consequently, the SSP will not elicit a sense of danger in older children and attachment strategies will not be observable (Rutter, Kreppner, \& SonugaBarke, 2009). Problems in the administration and analysis of the SSP in studies, including children with autism, have led some to question whether the SSP should be used at all with these children and whether it is possible to categorize their attachment behaviour given their autistic symptoms 
(Rutter et al., 2009). An alternative suggestion would be that the SSP and similar measures should be used for the age groups they are designed for and analysis should be standard. For older children, there are other measures, which can be used such as the Child Attachment Interview (ShmueliGoetz, Target, Fonagy, \& Datta, 2008).

The AQS is presented as a measure of attachment security, which has advantages over the SSP. The AQS consists of up to 100 cards, each describing a behavioural characteristic. After observing the child in a naturalistic setting, the cards are ranked according to best fit for a number of indicators of attachment security focusing on the secure base. The resulting profiles are compared with a standard descriptive profile of a secure child resulting in the AQS security score. Cards can be ranked by an observer or a parent. The AQS can be used without the need for distressing separations as in the SSP (van IJzendoorn, Vereijken, Bakermans-Kranenburg, \& Riksen-Walraven, 2004). While this is often seen as an advantage, it is also open to the same criticisms made of the modified SSP. Namely, where observational measures do not instigate states of mild danger such strategies will not be displayed. Additional difficulties stem from the use of the AQS as a selfreport measure. A series of meta-analyses, for example, revealed that the self-report AQS did not show sufficient validity as a measure of attachment security (van IJzendoorn et al., 2004).

As with the SSP, attempts have been made to modify the AQS to take account of autistic symptoms. In particular, socio-communicative deficits are hypothesized to result in atypical expression of attachment behaviours. This idea reflects a misunderstanding about the nature of attachment. The function of attachment behaviour is not predominantly social, but rather to protect oneself from potential danger. The conflation between the social deficits in autism and attachment behaviours has led to attempts to change measures of attachment security to accommodate atypical social behaviour in autism. In the case of the AQS, criterion sorts have been developed to provide prototypical secure profiles specific to children with autism (Rutgers, Van Ijzendoorn, BakermansKranenburg, \& Swinkels, 2007). All of the changes made to the original secure profile involve 'proximity seeking', the implication being that secure children with autism are less likely to seek proximity to the caregiver because of their autistic symptoms. A detailed knowledge of attachment theory would be in conflict with this assertion. Attachment strategies necessarily involve the child seeking safety in response to danger. Proximity to the caregiver is a fundamental feature of attachment theory and is hardwired to ensure survival. Only children with the most severely disorganized patterns would not seek proximity in times of danger. Any suggestion that secure behaviour involves a lack of proximity seeking is denying this essential tenet of attachment theory. Such a hardwired drive is quite distinct from any social deficits or preferences. If we accept the unlikely scenario that secure attachment in autism does not include a basic drive for young children to stay close to the primary source of safety, we must also accept that attachment behaviour may differ in a range of conditions. This would lead us to question whether attachment security can be assessed in any group other than typically developing children.

\section{The prevalence of attachment difficulties among children with autism}

The literature exploring the prevalence of insecure attachment among children with autism is complex and contradictory and includes misconceptions about attachment theory. In 2004, Rutgers et al. carried out a meta-study and narrative review exploring whether children with autism demonstrate similar distributions of attachment classifications as typical children. The meta-analysis explored 16 existing studies all of which, bar one, used adapted versions of the SSP. Analysis in all cases was on the basis of Ainsworth's ABC scores, although additional measures used included the 
AQS, Main and Solomon's (1990) coding system for disorganized attachment and Richters Security Score (1988). Rutgers et al. report substantial differences in the outcomes of the studies reviewed. For example, some studies found significantly less secure attachment among children with autism compared to typical controls (e.g. Bakermans-Kranenburg et al., 2003; Capps, Sigman, \& Mundy, 1994; Spencer, 1993), while others found comparable distributions of secure attachment to other groups. Overall, the meta-analysis concluded that children with autism are substantially less likely to be securely attached to their caregiver, but some children with autism can develop secure attachments, showing a preference for their mother over a stranger through engaging in proximity seeking. This definition of secure attachment, however, demonstrates misconceptions as children with insecure attachment patterns also engage in some proximity seeking under conditions of separation and show some preference for their attachment figure. Gross lack of proximity seeking and no display of preference for the attachment figure is a feature of only the most severely disorganized patterns associated with extreme trauma (Cassidy \& Shaver, 2008; Solomon \& George, 2011).

Rutgers et al. identify limitations in their study, including the combination of children with autism and pervasive developmental disorder not otherwise specified (PDD-NOS) in samples. Careful analysis reveals that attachment insecurity was significantly higher among children with autism compared to PDD-NOS, suggesting that conclusions about levels of insecure attachment in autism based on the whole sample were misleading. Other limiting factors included the inconsistency of measures, comparison groups and forms of analysis used. A further important drawback suggesting oversimplification of current knowledge of insecure attachment was the fact that the meta-analysis focused only on whether the children had secure or insecure attachment patterns and did not explore prevalence of different types of insecure attachment.

A comprehensive search for studies exploring attachment security among children with autism since 2004 shows similar measures have been used, in particular, versions of the SSP and the AQS. Findings continue to be mixed, but overall lead to the conclusion that children with autism have higher levels of attachment insecurity than comparison groups. As in previous studies, the most widely used measure was the SSP or modified SSP. For example, Naber et al. (2007) assessed attachment among toddlers with autism, PDD, learning disability and language development disorder using the SSP. The children with autism displayed significantly more insecure attachment than other groups, and levels of disorganized attachment were higher than other groups; this finding is consistent with previous findings (Capps et al., 1994; Willemsen-Swinkels et al., 2000).

Akdemir, Pehlivantürk, Unal and Ozusta (2009) studied attachment among mothers and their children with autism and developmentally disabled children between 28 and 51 months using the modified SSP, but also used the Relationship Scales Questionnaire, a brief measure of adult attachment styles (Griffin \& Bartholomew, 1994). Both groups of children showed similar attachment behaviours, but the children with autism had more distant and less reciprocal interactions with their mothers. Children with autism directed more attachment behaviours towards their mothers compared to the stranger, and this was seen as indicative of secure attachment, although attachment theory would predict that children with all but the most extreme insecure attachment patterns would prefer their mother over a stranger.

van IJzendoorn et al. (2007) assessed parental sensitivity and attachment security among 2-yearold children with autism, learning disability, language delays and typical development using the SSP and The Emotional Availability Scales (Biringen, Robinson, \& Emde, 2000). They found that parental sensitivity did not significantly differ between groups, but children with autism were less securely attached than comparison children, were more disorganized and interacted less with parents. Parental sensitivity was associated with attachment security among the non-autistic children (including those with learning difficulties) but not among the children with autism. 
Other studies used the AQS or variations of it, including the Brief Attachment Screening Questionnaire. For example, Zhong, Cui and Zou (2011) used the AQS to assess attachment security among children with autism compared to typical children and found more than $70 \%$ of them exhibited insecure attachment. Rutgers et al. (2007) used the Brief Attachment Screening Questionnaire, based on 12 items of the AQS, to assess attachment in children with autism, mental retardation, language disorder and non-clinical children and found that children with autism had less attachment security than comparison groups.

Although it is difficult to draw conclusions from this literature, in many studies children with autism exhibit more attachment insecurity than typical children, although some studies show levels of attachment security among children with autism approaching levels found in typical children. A dissatisfaction with existing measures and consequent modifications would appear to reflect an expectation that the prevalence of secure attachment in autism should be similar to that found in the typical population. Children with autism are subject to risk factors, however, which increase the likelihood of autism and attachment difficulties coinciding.

\section{Why might autism and attachment difficulties coincide?}

Overall, although the literature on the prevalence of attachment difficulties in autism is confusing, it appears that children with autism show higher levels of insecure attachment than typical children and other clinical groups. This is not surprising as there is evidence from a variety of sources suggesting that children with autism and their parents may be subject to particular stresses, which make secure attachments less likely. A major misconception in considering patterns of insecure attachment is that maltreatment or severe lack of care must be the cause. In reality, most insecure attachment is the result of well-intentioned action in difficult circumstances (Dallos, 2006; Marvin \& Stewart, 1990).

Mental health problems are known to substantially increase risk of insecure attachment patterns in adults and their children (Berry \& Drake, 2010; Ma, 2006). Mental health problems are experienced by more than $70 \%$ of individuals with autism and more than $50 \%$ of their parents (Dykens, Fisher, Taylor, Lambert, \& Miodrag, 2014; Hallett et al., 2013). Individuals with autism suffer from high levels of anxiety and depression compared to those with other developmental conditions (e.g. Brereton, Tonge, \& Einfeld, 2006). Families of children with autism have higher rates of depression, anxiety and social phobia, than families with typically developing children, or children with other developmental disorders (Mazefsky, Folstein, \& Lainhart, 2008). Parents of children with autism are also more likely to be hospitalized for mental disorders than parents of typical children (Daniels et al., 2008).

One major factor in the development of insecure attachment patterns is the caregiver's own experience of being parented. Where parents have not experienced positive relationships they are likely to have ongoing difficulties, including mental health problems and to lack models of secure parenting. Our own work with families and related literature indicates that parents of children with autism have frequently experienced early trauma and abuse (McKenzie \& Dallos, 2017). There is evidence to suggest that maternal exposure to abuse in childhood significantly increases the risk of having a child with autism (Roberts, Lyall, Rich-Edwards, Aschorio, \& Weisskopf, 2013). It is also reported that women who have children with autism are significantly more likely than other mothers to have suffered from post traumatic stress disorder and to have experienced extreme physical or emotional abuse prior to the birth of the child (Roberts, Koenen, Lyall, Ascherio, \& Weisskopf, 2014). Unresolved trauma is known to impede parenting abilities and is associated with insecure attachment and the development of severe forms of pathology in children. Evidence suggests that parenting children with autism also involves particular stresses associated with maladaptive 
behaviour, lack of empathy and emotional feedback from the child (Pisula, 2011). Consequently, mothers of children with autism may struggle to cope and have higher unmet needs than parents of children with other disabilities (Siklos \& Kerns, 2008).

The study of relational factors associated with the development of autism has been a neglected area of study in the wake of Bettelheim's (1967) work on the causes of autism, which was felt to unnecessarily blame mothers. The backlash to Bettelheim's theory resulted in a reluctance to explore relational factors, particularly child-caregiver interaction (Bishop et al., 2004; Sivaratnam, Newman, Tonge, \& Rinehart, 2015). It is well known, however, that the symptoms of autism result in poor communicative cues among children who may avoid eye contact with caregivers, lack social reciprocity and fail to attend to social stimuli (Bieberich \& Morgan, 1998). Such symptoms are highly likely to interfere with early attachment between infants and caregivers. There is evidence that a lack of communicative cues exhibited by children with autism arouses less insight and reflection among parents in narratives about their children, compared to parents of typical children or children with other developmental difficulties (Hutman, Siller, \& Sigman, 2009). In addition, the Broad Autism Phenotype is disproportionally represented among family members of children with autism and many parents have autistic traits (Sasson, Lam, Parlier, Daniels, \& Piven, 2013). Hence, they can share some or all of the symptoms of autism with their children and their sociocommunicative skills, including Theory of Mind, are likely to be compromised. This obviously has implications for identifying and responding to their infant's needs. For example, it has been suggested that difficulties in interpreting the needs of infants characterize very early attachments between children with autism and their parents, resulting in negative feedback loops where difficulties experienced by child and parent are mutually exacerbating. Such feedback loops can initiate and escalate potentially difficult family relationships and contribute to autistic symptomology (Crittenden, Dallos, Kowloska, \& Landini, 2014). There are few studies which question whether affective disorders combined with autistic traits among parents pose an environmental risk for the development of autism. Limited work demonstrates, however, that a child's risk of developing autism is doubled if both parents have a personality or psychiatric disorder (Mazefsky et al., 2008) and parents of children with autism report that lack of psychological wellbeing exacerbates maladaptive behaviour in their children (Nikmat, Ahmad, Oon, \& Razali, 2008).

Where such risks are present, autism and attachment difficulties may converge very early in development. Forming a secure attachment with an infant with autism, who is unresponsive, is extremely challenging especially when faced with substantial negative feedback leading to stress and uncertainty (Slade, 2009). Consequently, the likelihood of insecure attachment in dyads where an infant has autistic traits is high even for the most attentive parent (van IJzendoorn et al., 2007). In cases where the caregiver is suffering from mental health problems or unresolved trauma and has negative parenting models, the possibility of insecure attachment is extremely high.

Insecure attachment has both psychological and neurological implications (See Schore \& Schore, 2008 for a review). Children with early insecure attachment patterns exhibit poorer social, emotional, behavioural and academic outcomes compared to secure children (Goldberg, 1997; Kennedy \& Kennedy, 2004). Such outcomes include deficits in verbal communication (e.g. Maunder, Lancee, Nolan, Hunter, \& Tannenbaum, 2006), non-verbal communication and Theory of Mind (Schachner, Shaver, \& Mikulincer, 2005). Additional outcomes include social and emotional distancing and isolation (Larose \& Bernier, 2001) aggressive anti-social behaviour (Renken, Egeland, Marvinney, Mangelsdorf, \& Sroufe, 1989) low self-confidence, hypersensitivity, over stimulation (Sroufe, Fox, \& Pancake, 1983) and increased risk of developing psychopathology (Kennedy \& Kennedy, 2004).

Children with autism may develop a complex set of symptoms derived from the developmental implications of autistic traits, combined with insecure attachment, leading to a blurring and 
exacerbation of symptoms associated with the two conditions. Over time, the symptoms of one condition may mask the other or may become so entangled that it is no longer possible for clinicians to distinguish which symptoms may be attributable to autism. This is true of many cases where psycho-pathological conditions are comorbid with autism (Mazzone \& Vitiello, 2016), but diagnostic complexity is compounded in the case of comorbidity with attachment difficulties due to early onset and the similarity of core symptoms.

\section{Secure attachment in autism}

As we have seen, the literature on attachment and autism is complex, but it does suggest that children with autism can form secure attachments with their caregivers. Several studies show that where mothers of children with autism are particularly sensitive, they are able to establish secure attachments with their children despite subtle, odd, overwhelming, inconsistent or absent cues from the child (Capps et al., 1994; Siller \& Sigman, 2002; Slade, 2009). Importantly, this ability among some mothers has been shown to be unrelated to the severity of the child's symptoms (Koren-Karie, Oppenheim, Dolev, \& Yirmiya, 2009). The outcomes for these children compared to insecurely attached children with autism include increased engagement and social initiation (Capps et al., 1994); reduced behaviour problems (Baker, Messinger, Lyons, \& Grantz, 2010), more instances of joint attention, more reciprocal smiling and turn-taking behaviour, increased evidence of Theory of Mind (Seskin et al., 2010) and enhanced language development (Baker et al., 2010; Siller \& Sigman, 2002). The Siller and Sigman study explored the association of synchrony between children with autism and caregiver over a period of 16 years. This study indicates that the caregiver's ability to provide non-demanding synchronous cues may be of particular importance in supporting the longterm development of communication, as in typically developing children (Carpenter, Nagell, \& Tomasello, 1998). Similar to previous findings, synchrony was not found to be related to the severity of impairment within the children. These studies strongly suggest that evidence-based relational and attachment-based interventions which improve dyadic synchrony and sensitivity of parents may lead to improvements in autistic symptomology for children with both mild and severe symptoms.

\section{Formulation as an innovative solution}

Studies of secure attachment systems in autism highlight the importance of considering the relationships around the child in understanding symptoms and offering appropriate intervention. Formulation is an innovative alternative to current diagnostic procedures and consequent choice of intervention. Formulation circumvents the problems associated with overlap of symptoms by identifying the needs and relational context of the family. As the symptoms of autism and attachment overlap so substantially, attempts to distinguish between difficulties on the basis of symptom presentation alone may be less fruitful than an integrative formulation approach. This can combine a focus on individual factors with a systemic analysis of interactional patterns of infant-caregiver feedback processes (Johnstone \& Dallos, 2013). Likewise, Crittenden (2015) suggests a focus on understanding what course of treatment is most appropriate rather than on categorizing the symptoms by matching them to diagnostic criteria. This involves a 'family functional formulation' where an in-depth understanding of the relationships around the 'patient' is gained through assessment of attachment strategies, history of exposure to danger for family members and consequent areas of family conflicts. Such an approach might be particularly useful for understanding the potentially complex interrelated biological, developmental and relational reasons why children display symptoms that indicate autism and how maladaptive symptoms and parental distress might be alleviated. 
Formulation presents a useful alternative to traditional diagnostic procedures and intervention for individuals with autism for a number of reasons. Formulation is a more case-specific approach that can accommodate symptom variation found in a spectrum condition. Formulation can also address the lack of a definitive diagnostic test for autism by focusing on the specific, idiographic analysis of the relationships and experiences around the child as a means of building a profile of difficulties and strengths. Because formulation works with the people in the child's life and includes assessment of attachment strategies, it is also particularly useful in identifying where attachment difficulties are the core feature of the child's and the caregiver's experience. Formulation can help to identify circular feedback processes, which maintain and exacerbate maladaptive symptoms (see Figure 1). Attachment insecurities and autistic traits can interact to produce increasing anxiety and confusion about problems faced, which in turn further exacerbates autistic symptoms and attachment problems. Identifying such feedback processes can help signpost appropriate interventions, which focus on both the child and other family members. An important aspect of a family formulation approach is that feelings of failure and anxiety can be alleviated, by validating the parents' intentions to replicate positive patterns of behaviour or correct negative patterns of behaviour (Byng-Hall, 1995). This can help move beyond some of the sense of blaming that has resulted from earlier studies of mother-infant interactions in relation to autism.

Formulation is often presented as an alternative to current diagnostic processes, but aspects of a formulation approach can be used as part of existing clinical assessments. For example, Fletcher, Flood and Hare (2016) suggest that clinical interviews with an attachment lens, alongside observations should be of central importance when assessing and working clinically with families of children with autism. Where such approaches are integrated into early assessments, diagnosis and subsequent support can be informed by in-depth understanding of issues around the child.

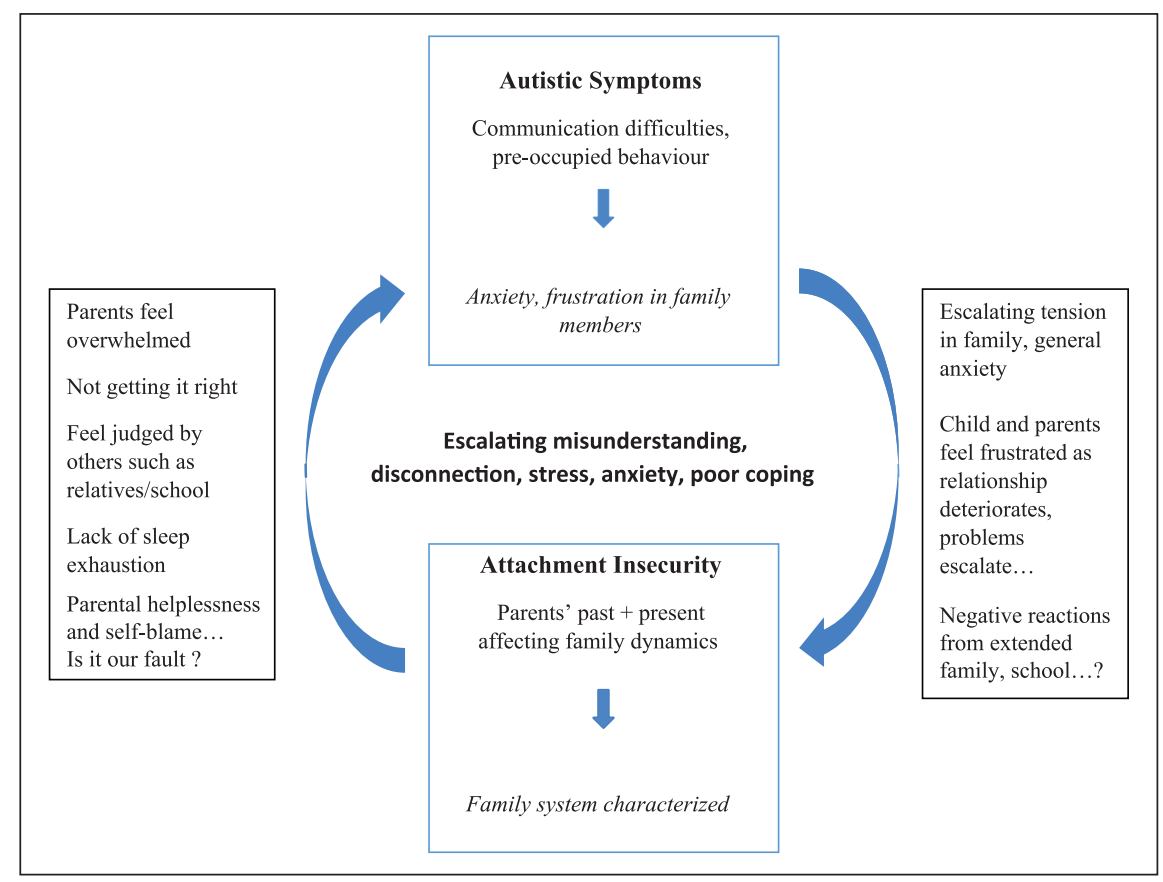

Figure I. Formulation of the interaction between symptoms of autism and insecure attachment. 
Formulation can be described as having two intertwined strands: assessment and ongoing treatment planning and refinement. Formulation within systemic practice involves initial information gathering, but also working with families to progressively co-construct working hypotheses about problems and work towards positive change (Johnstone \& Dallos, 2013). This systemic approach informs, therefore, not only the assessment of need and appropriate intervention, but also how the intervention should progress (Vetere \& Dallos, 2003). Despite the existence of a wide range of interventions associated with autism, families report a lack of support after diagnosis and a failure of available interventions to meet their needs (Wallace, Parr, \& Hardy, 2013). Many interventions fail to acknowledge the experience of the wider family including mental health issues, trauma and high levels of autistic traits. In addition, the strengths of these families in the face of substantial challenges are often ignored leading to a sense of blame and hopelessness. Formulation offers, not only the potential for identifying appropriate intervention, but also the possibility of a systemic approach to the intervention itself, which allows ongoing consideration of attachment and contextual factors within the family. Such an approach is epitomized by interventions, which are based on family therapy. A number of interventions show promise in this regard (Dallos \& McKenzie, 2016; Monteiro, 2016; Procter, 2000; Simon, 2004).

Formulation also offers possibilities to address the lengthy wait many families experience prior to diagnosis and treatment. Formulation centres on assessment of need rather than identification of specific symptoms associated with a condition. There is in principle, therefore, no reason why initial assessments based on formulation and systemic approaches to treatment could not be used as soon as families are referred. There is ample evidence that early intervention can have positive outcomes and early symptoms need not be deterministically related to later deficits (Le Couteur et al., 1996). A number of family therapy-based interventions not only provide opportunities for early intervention, but also acknowledge preferences, which are over-represented in autism such as special interests and enhanced visual processing. For example, SAFE (Dallos \& McKenzie, 2016) and Monteiro's Narrative Family Therapy approach (Monteiro, 2016) are based not only on established principles of family therapy, but also on current research about preferences and behaviours associated with autism.

\section{Conclusion}

This paper draws together evidence from the literature surrounding autism and attachment and indicates problems with implications for both researchers and clinicians. We respond to some of the difficulties identified by presenting recommendations for change. For example, we suggest that additional work needs to be done to establish validity of standard attachment measures such as the SSP with children who have developmental disorders. Modifications to attachment measures used in research and clinical practice should be informed by a more careful consideration of the fundamental premises of attachment theory. Use of the SSP should take account of the age group it was designed for. Possible measures, which are more appropriate for older children and could be used in both research and clinical contexts, include the Story Stem Assessment Profile (Hodges, Hillman, Steele, \& Henderson, 2007) and the Child Attachment Interview (Shmueli-Goetz et al., 2008). Clinical assessments should include routine consideration of attachment issues, but avoid being driven only by categorizing symptoms for diagnostic purposes. We suggest that formulation, which focuses on identifying need and responding to need, may be more fruitful than current diagnostic procedures and may contribute to earlier intervention. In particular, recognizing that there are frequently escalating negative processes between attachment insecurity and autistic symptomology supports the need for early family attachment-based interventions. These recommendations are not 
only specific to work with families affected by autism, but also connect with more general calls for change in both research and clinical practice.

\section{Declaration of Conflicting Interests}

The author(s) declared no potential conflicts of interest with respect to the research, authorship, and/or publication of this article.

\section{Funding}

The author(s) received no financial support for the research, authorship and/or publication of this article.

\section{References}

Ainsworth, M. D., Blehar, M. C., Waters, E., \& Wall, S. (1978). Patterns of attachment: A psychological study of the strange situation. Hillsdale, NJ: Lawrence Erlbaum.

Akdemir, D., Pehlivantürk, B., Unal, F., \& Ozusta, S. (2009). Comparison of attachment-related social behaviours in autistic disorder and development disability. Turkish Journal of Psychiatry, 20, 105-117.

American Psychiatric Association. (2013). Diagnostic and statistical manual of mental disorders (5th ed.). Arlington, VA: American Psychiatric Publishing.

Baker, J. K., Messinger, D. S., Lyons, K. K., \& Grantz, C. J. (2010). A pilot study of maternal sensitivity in the context of emergent autism. Journal of Autism and Developmental Disorders, 40, 988-999.

Bakermans-Kranenburg, M. J., Rutgers, A. H., Willemsen-Swinkels, S. H. N., \& van IJzendoorn, M. H. (2003, August). Attachment in children with autism. Paper presented at the XIth European Conference on Developmental Psychology, Milan, Italy.

Berry, K., \& Drake, R. (2010). Attachment theory in psychiatric rehabilitation: Informing clinical practice. Advances in Psychiatric Treatment, 16, 308-315.

Bettelheim, B. (1967). The Empty Fortress: Infantile Autism and the Birth of the Self. New York, NY: The Free Press.

Bieberich, A. A., \& Morgan, S. B. (1998). Brief report: Affective expression in children with autism or Down syndrome. Journal of Autism and Developmental Disorders, 28, 333-338.

Biringen, Z., Robinson, J., \& Emde, R. N. (2000). The emotional availability scales (3rd ed.). Attachment and Human Development, 2, 256-270.

Bishop, D. V., Maybery, M., Maley, A., Wong, D., Hill, W., \& Hallmayer, J. (2004). Using self-report to identify the broad phenotype in parents of children with autistic spectrum disorders: A study using the autism-spectrum quotient. The Journal of Child Psychology and Psychiatry, and Allied Disciplines, 45, $1431-1436$.

Brereton, A. V., Tonge, B. J., \& Einfeld, S. L. (2006). Psychopathology in children and adolescents with autism compared to young people with intellectual disability. Journal of Autism and Developmental Disorders, 36, 863-870.

Byng-Hall, J. (1995). Rewriting family scripts: Improvisations and systems change. New York, NY: Guilford Press.

Capps, L., Sigman, M., \& Mundy, P. (1994). Attachment security in children with autism. Development and Psychopathology, 6, 249-261.

Carpenter, M., Nagell, K., \& Tomasello, M. (1998). Social cognition, joint attention, and communicative competence from 9 to 15 months of age. Monograph of the Society for Research in Child Development, 63(4), i-vi, 1-143.

Cassidy, J., \& Shaver, P. R. (Eds.). (2008). Handbook of attachment: Theory research and clinical applications (2nd ed.). London, England: Guilford Press.

Crittenden, P. M. (2006). A dynamic-maturational model of attachment. Australian \& New Zealand Journal of Family Therapy, 27, 105-115.

Crittenden, P. M. (2015). Raising Parents. London, England: Routledge. 
Crittenden, P. M., Dallos, R., Kowloska, K., \& Landini, A. (2014). Attachment \& family therapy. Maidenhead, UK: Open University Press/McGraw-Hill.

Dallos, R. (2006). Attachment Narrative Therapy: Integrating systemic narrative and attachment approaches. Maidenhead, UK: Open University Press.

Dallos, R., \& McKenzie, R. (2016). SAFE intervention manual. Available from http://www.safefamily.org. uk/

Daniels, J. L., Forssen, U., Hultman, M., Cnattingius, S., Savitz, D. A., Feychting, M., \& Spraren, P. (2008). Parental psychiatric disorders associated with autism spectrum disorders in the offspring. Pediatrics, $121,1357-1162$.

Davidson, C., O'Hare, A., Mactaggart, F., Green, J., Young, D., Gillberg, C., \& Minnis, H. (2015). Social relationship difficulties in autism and reactive attachment disorder: Improving diagnostic validity through structured assessment. Research in Developmental Disabilities, 40, 63-72.

Dykens, E. M., Fisher, M. H., Taylor, J. L., Lambert, W., \& Miodrag, N. (2014). Reducing distress in mothers of children with autism and other disabilities: A randomized trial. Pediatrics, 134(2), e454.

Fletcher, H. K., Flood, A., \& Hare, D. J. (2016). Attachment in intellectual and developmental disability: A clinician's guide to practice and research. Hoboken, NJ: John Wiley.

Goldberg, S. (1997). Attachment and childhood behavior problems in normal, at-risk and clinical samples. In L. Atkinson \& K. J. Pucker (Eds.), Attachment and psychopathology (pp. 171-195). New York, NY: Milford Press.

Green, J., Leadbitter, K., Kay, C., \& Sharma, K. (2016). Autism spectrum disorder in children adopted after early care breakdown. Journal of Autism and Developmental Disorders, 46, 1392-1402.

Griffin, D., \& Bartholomew, K. (1994). Metaphysics of measurement: The case of adult attachment. In K. Bartholomew \& D. Perlman (Eds.), Advances in personal relationships, Vol. 5: Attachment processes in adulthood (pp. 17-52). London, England: Jessica Kingsley.

Grzadzinski, R. L., Luyster, R., Spencer, A. G., \& Lord, C. (2014). Attachment in young children with autism spectrum disorders: An examination of separation and reunion behaviors with both mothers and fathers. Autism, 18, 85-96.

Hallett, V., Ronald, A., Colvert, E., Ames, C., Woodhouse, E., Lietz, S., . . Happe, F. (2013). Exploring anxiety symptoms in a large-scale twin study of children with autism spectrum disorders, their co-twins and controls. The Journal of Child Psychology and Psychiatry, and Allied Disciplines, 54, 1176-1185.

Hodges, J., Hillman, S., Steele, M., \& Henderson, K. (2007). Story Stem Assessment Profile (SSAP) Coding Mannual, GOS/AFC/Coram Study, 2007 revision. Unpublished manuscript,Anna Freud Centre, London, England.

Hoksbergen, R., Laak, J., Rijk, K., Dijkum, C., \& Stoutjesdijk, F. (2005). Post-institutional autistic syndrome in Romanian adoptees. Journal of Autism and Developmental Disorders, 35, 615-623.

Hutman, T., Siller, M., \& Sigman, M. (2009). Mothers' narratives regarding their child with autism predict maternal synchronous behavior during play. The Journal of Child Psychology and Psychiatry, and Allied Disciplines, 50, 1255-1263.

Johnstone, L., \& Dallos, R. (2013). Formulation in psychology and psychotherapy: Making sense of people's problems. London, England: Routledge.

Kennedy, J. H., \& Kennedy, C. E. (2004). Attachment theory: Implications for school psychology. Psychology in the Schools, 41, 247-259.

Koren-Karie, N., Oppenheim, D., Dolev, S., \& Yirmiya, N. (2009). Mothers of securely attached children with autism spectrum disorder are more sensitive than mothers of insecurely attached children. The Journal of Child Psychology and Psychiatry, and Allied Disciplines, 50, 643-650.

Larose, S., \& Bernier, A. (2001). Social support processes: Mediators of attachment state of mind and adjustment in late adolescence. Attachment \& Human Development, 3, 96-120.

Le Couteur, A., Bailey, A., Goode, S., Pickles, A., Robertson, S., Gottesman, I., \& Rutter, M. (1996). A broader phenotype of autism: The clinical spectrum in twins. The Journal of Child Psychology and Psychiatry, and Allied Disciplines, 37, 785-801.

Ma, K. (2006). Attachment theory in adult psychiatry. Part 1: Conceptualisations, measurement and clinical research findings. Advances in Psychiatric Treatment, 12, 440-449. 
Main, M., \& Solomon, J. (1986). Discovery of a new, insecure disorganized/disoriented attachment pattern. In T. B. Brazelton, \& M. Yogman (Eds.), Affective development in infancy (pp. 95-124). Norwood, NJ: Ablex.

Main, M., \& Solomon, J. (1990). Procedures for identifying disorganized/disoriented infants during the Ainsworth strange situation. In M. Greenberg, D. Cicchetti, \& M. Cummings (Eds.), Attachment in the preschool years (pp. 121-160). Chicago, IL: The University of Chicago Press.

Marvin, R. S., \& Stewart, R. B. (1990). A family systems framework for the study of attachment. In M. T. Greenberg, D. Ciccetti, \& E. M. Cummings (Eds.), Attachment in the pre-school years (pp. 51-86). Chicago, IL: The University of Chicago Press.

Maunder, R. G., Lancee, W. J., Nolan, R. P., Hunter, J. J., \& Tannenbaum, D. W. (2006). The relationship of attachment insecurity to subjective stress and autonomic function during standardized acute stress in healthy adults. Journal of Psychosomatic Research, 60, 283-290.

Mazefsky, C. A., Folstein, S. E., \& Lainhart, J. E. (2008). Overrepresentation of mood and anxiety disorders in adults with autism and their first degree relatives: What does it mean? Autism Research, 1, 193-197.

Mazzone, L., \& Vitiello, B. (2016). Psychiatric symptoms and comorbidities in autism spectrum disorder. New York, NY: Springer.

McKenzie, R., \& Dallos, R. (2017). Autism and Family Dynamics. Manuscript in preparation.

Meltzer, H., Gatward, R., Corbin, T., Goodman, R., \& Ford, T. (2003). The mental health of young people looked after by local authorities in England. London, England: Office for National Statistics, The Stationary Office.

Monteiro, M. (2016). Family therapy and the autism spectrum: Autism conversations in narrative practice. London, England: Routledge.

Moran, H. (2010). Clinical observations of the differences between children on the autism spectrum and those with attachment problems: The Coventry grid. Good Autism Practice, 11(2), 46-59.

Naber, F. B. A., Swinkles, S. H., Buitelaar, J. K., Bakermans-Kranenburg, M. J., van IJzendoorn, M. H., Dietz, C., . . .van Engeland, H. (2007). Attachment in toddlers with autism and other developmental disorders. Journal of Autism and Developmental Disorders, 37, 1123-1138.

Nikmat, A. W., Ahmad, M., Oon, N. L., \& Razali, S. (2008). Stress and psychological wellbeing among parents of children with autism spectrum disorder. ASEAN Journal of Psychiatry, 9(2), 65-72.

Ozonoff, S., Williams, B. J., \& Landa, R. (2005). Parental report of the early development of children with regressive autism: The delays-plus-regression phenotype. Autism, 9, 461-486.

Pisula, E. (2011). Parenting stress in mothers and fathers of children with autism spectrum disorders. In M.-R. Mohammadi (Ed.), A comprehensive book on autism spectrum disorders. Retrieved from http:// www.intechopen.com/books/a-comprehensive-book-on-autism-spectrum-disorders/parenting-stress-inmothers-and-fathers-of-children-with-autism-spectrum-disorders

Procter, H. G. (2000). Autism and Family Therapy: A personal construct approach. In S. Powell (Ed.), Helping children with autism to learn. London, England: David Fulton.

Renken, B., Egeland, B., Marvinney, D., Mangelsdorf, S., \& Sroufe, L. A. (1989). Early childhood antecedents of aggression and passive-withdrawal in early elementary school. Journal of Personality, 57, $257-281$.

Roberts, A. L., Koenen, K. C., Lyall, K., Ascherio, A., \& Weisskopf, M. G. (2014). Women's posttraumatic stress symptoms and autism spectrum disorder in their children. Research in Autism Spectrum Disorders, $8,608-616$.

Roberts, A. L., Lyall, K., Rich-Edwards, J. W., Aschorio, A., \& Weisskopf, M. (2013). Association of maternal exposure to childhood abuse with elevated risk for autism in offspring. JAMA Psychiatry, 70, 508-515.

Rutgers, A. H., Bakermans-Kranenburg, M. J., van IJzendoorn, M. H., \& van Berckelaer-Onnes, I. A. (2004). Autism and attachment: A meta-analytic review. The Journal of Child Psychology and Psychiatry, and Allied Disciplines, 45, 1123-1134.

Rutgers, A. H., van IJzendoorn, M. H., Bakermans-Kranenburg, M. J., Swinkels, S. H., van Daalen, E., Dietz, C., . . Engeland, H. (2007). Autism, attachment and parenting: A comparison of children with autism spectrum disorder, mental retardation, language disorder, and non clinical children. Journal Abnormal Child of Psychology, 35, 859-870. 
Rutgers, A. H., van IJzendoorn, M. H., Bakermans-Kranenburg, M. J., \& Swinkels, S. H. (2007). Autism and Attachment: The Attachment Q-Sort. Autism, 11(2), 187-200.

Rutter, M., Anderson-Wood, L., Beckett, C., Brendenkamp, D., Castle, J., Grootheus, C., . . O'Connor, T. G. (1999). Quasi-autistic patterns following severe early global privation. The Journal of Child Psychology and Psychiatry, and Allied Disciplines, 40, 537-549.

Rutter, M., Kreppner, J., \& Sonuga-Barke, E. (2009). Emanuel miller lecture: Attachment insecurity, disinhibited attachment, and attachment disorders: Where do research findings leave the concepts? The Journal of Child Psychology and Psychiatry, and Allied Disciplines, 50, 529-543.

Sadiq, F., Slater, L., Skuse, D., Law, J., Gillberg, C., \& Minnis, H. (2012). Social use of language in children with reactive attachment disorder and autism spectrum disorders. European Child \& Adolescent Psychiatry, 21, 267-276.

Sasson, N. J., Lam, K. S. L., Parlier, M., Daniels, J. L., \& Piven, J. (2013). Autism and the broad autism phenotype: Familial patterns and intergenerational transmission. Journal of Neurodevelopmental Disorders, $5,11-18$.

Schachner, D. A., Shaver, P. R., \& Mikulincer, M. (2005). Patterns of nonverbal behavior and sensitivity in the context of attachment relationships. Journal of Nonverbal Behavior, 29, 141-169.

Schore, J. R., \& Schore, A. N. (2008). Modern attachment theory: The central role of affect regulation in development and treatment. Clinical Social Work Journal, 36, 9-20.

Seskin, L., Feliciano, E., Tippy, G., Yedloutschnig, R., Sossin, K. M., \& Yasik, A. (2010). Attachment and autism: Parental attachment representations and relational behaviors in the parent-child dyad. Journal of Abnormal Child Psychology, 38(7), 949-960.

Shirataki, S. (1994, July). Abnormal attachment relationship as an early sign of autistic disorders. Presented at the 13th International Congress of IACAPAP, San Francisco, CA.

Shmueli-Goetz, Y., Target, M., Fonagy, P., \& Datta, A. (2008). The child attachment interview: A psychometric study of reliability and discriminant validity. Developmental Psychology, 44, 939-956.

Siklos, S., \& Kerns, K. A. (2008). Assessing need for social support in parents of children with autism and Down syndrome. Journal of Autism and Developmental Disorders, 36, 921-933.

Siller, M., \& Sigman, M. (2002). The behaviors of parents of children with autism predict the subsequent development of their children's communication. Journal of Autism and Developmental Disorders, 32, $77-89$.

Simon, G. (2004). Systemic family therapy with families with a child who has a diagnosis of asperger syndrome. Human Systems: The Journal of Systemic Consultation and Management, 15, 257-274.

Sivaratnam, C. S., Newman, L., Tonge, B., \& Rinehart, N. J. (2015). Attachment and emotion processing in children with autism spectrum disorders: Neurobiological, neuroendocrine, and neurocognitive considerations. Review Journal of Autism and Developmental Disorders, 2, 222-242.

Slade, A. (2009). Mentalizing the unmentalizable: Parenting children on the spectrum. Journal of Infant, Child, and Adolescent Psychotherapy, 8, 7-21.

Solomon, J., \& George, C. (Eds.). (2011). Disorganised attachment and caregiving. New York, NY: Guilford Press.

Spencer, A. G. (1993). Attachment behaviors in children with autism. Dissertation Abstracts International, $54,1321$.

Sroufe, L. A., Fox, N. E., \& Pancake, V. R. (1983). Attachment and dependency in developmental perspective. Child Development, 54, 1615-1627.

Stinehart, M., Scott, D. A., \& Barfield, H. G. (2012). Reactive attachment disorder in adopted and foster care children: Implications for mental health professionals. The Family Journal, 20, 335-360.

van IJzendoorn, M. H., Rutgers, A. H., Bakermans-Kranenburg, M. J., Swinkels, S. H. N., van Daalen, E., Dietz, C., . . van Engeland, H. (2007). Parental sensitivity and attachment in children with autism spectrum disorder: Comparison with children with mental retardation, with language delays, and with typical development. Child Development, 78, 597-608.

van IJzendoorn, M. H., Vereijken, C. M. J., Bakermans-Kranenburg, M. J., \& Riksen-Walraven, J. M. (2004). Assessing attachment security with the attachment Q sort: Meta-analytic evidence for the validity of the observer AQS. Child Development, 75, 1188-1213. 
Vetere, A., \& Dallos, R. (2003). Working systemically with families: Formulation, intervention and evaluation. London, England: Karnak.

Wallace, S., Parr, J., \& Hardy, A. (2013). One in a hundred: Putting families at the heart of autism research. London, England: Autistica.

Waters, E., \& Deane, K. (1985). Defining and assessing individual differences in attachment relationships: Q-methodology and the organization of behavior in infancy and early childhood. In I. Bretherton, \& E. Waters (Eds.), Growing points of attachment theory and research (Monographs of the Society for Research in Child Development, Vol. 50, Serial No. 209, pp. 41-65).

Willemsen-Swinkels, S. H. N., Bakermans-Kranenburg, M. J., Buitelaar, J. K., Van IJzendoorn, M. H., \& Van Engeland, H. (2000). Insecure and disorganized attachment in children with a pervasive developmental disorder: Relationship with social interaction and heart rate. The Journal of Child Psychology and Psychiatry, and Allied Disciplines, 41, 759-767.

Zhong, X., Cui, Q., \& Zou, X. (2011). Attachment quality and influential factors in 2-6years old children with autism. Journal of Applied Clinical Pediatrics, 26(18), 1436-1438.

\section{Author Biographies}

Rebecca McKenzie is a Developmental Psychologist who has worked with children with autism and their families for more than ten years. She is a lecturer in Early Childhood Studies at the University of Plymouth and runs the Plymouth Autism Network.

Rudi Dallos is a Professor and Research Director on the doctorate in clinical psychology training program at the University of Plymouth. He has worked as a clinician and family therapist and developed SAFE, a family therapy based intervention for families of children with autism. 